\title{
MEMOIRS
}

ON SOME

\section{PRINCIPLES OF PATHOLOGY}

IN THE

\section{NERVOUS SYSTEM.}

Br MARSHALL HALL, M.D., F.R.S. L. \& E., \&c.

READ NOVEMBER 10TH, 1840.

MEMOIR IV.

On the Plan of Observation of Diseases of the Nervous System.

I HAVE been much struck by an observation of Sir J. F. Herschel, which, however different the occasion on which it was made, is not less applicable to the subject which I wish once more to bring before this Society :

"The recent investigations" " will not only throw theoretical light on this very obscure subject,"* " but (what is at present quite as much wanted) arouse the attention of observers, and at the same time give it a right direction, by pointing out what ought to be observed, without which all observation is but lost labour." $\dagger$

* Of the Tides.

† Treatise on Astronomy, p. 338, note.

G 2 
If we wish to pursue the subject of clinical observation in general, we have fortunately a perfect model and example in the writings of $\mathbf{M}$. Louis.

But the object of the present Memoir is more restricted. My design is to point out "what ought to be observed" in a particular class of diseases, viz. those of the nervous system, and especially to point out some new objects of inquiry in regard to them.

In my three former Memoirs I have treated-

1. Of the condition of the muscular irritability in paralytic limbs;

2. Of the morbid reflex and retrograde actions of the spinal marrow; and

3. Of the distinct influence of volition, of emotion, and of the vis nervosa, in diseases of the nervous system.

I now proceed to lay before the Society the Plan of Observation to be adopted in their further investigation.

Sufficient has now been done to show that we must, in all such investigations, view the nervous system as sub-divided, not into the cerebro-spinal, and the ganglionic, but into the cerebral, the truespinal, and the ganglionic; and that in considering each disease of the nervous system, we must trace its influence distinctly in these three sub-divisions of that system; or, to state this view more emphatically, we must inquire,-

1. What are the distinct diseases of the cerebral, of 
the true-spinal, and of the ganglionic sub-divisions of the nervous system?

2. What is the influence of disease of one of these systems on the other two respectively?

3. In what order is that influence manifested?

Besides these important questions, there are several others not less momentous. They are these,-

1. What are the effects of irritation and of counterirritation, of pressure and of counter-pressure, in diseases within the cranium, or the spinal canal?

2. What is the special anatomy of the base of the encephalon, and its relation to cerebral diseases?

. 3. Why, with similar symptoms, have we dissimilar morbid appearances within the cranium; and vice versâ ?

4. What are the diseases of the nervous system in which we find, generally speaking, no morbid appearances on a post-mortem examination?

That these questions are of deep practical interest will soon become very apparent; and it is especially as an aid to the diagnosis of the seat and progress of diseases of the nervous system that these views are most important. I shall proceed to treat of these subjects briefly, as in my former Memoirs.

I.-What are the distinct diseases of the cerebral, the true-spinal, and the ganglionic systems; their mutual influence, and the order in which they are manifested?

If disease be limited to the cerebrum, its influence is limited to the cerebral functions. If 
from the cerebrum it extends its influence to the true spinal marrow, the functions of this latter are involved, and spinal symptoms are added to the cerebral; or with the cerebral the spinal functions are impaired. This latter condition may frequently be detected by using the reflex function as a test; and in this manner the views of this function, which have recently been laid before the profession and before this Society, come to have their practical application. They afford, indeed, a new source of Diagnosis of the nature, seat, and extent of diseases of the nervous system, and consequently of their Prognosis.

If the disease be limited in its effects to the true spinal marrow, the symptoms are exclusively spinal, sometimes in excess, sometimes in a defective form. If the cerebral system become also involved, cerebral symptoms are superadded to the spinal.

Similar remarks may doubtless be made in regard to the ganglionic system, viewed in its connections and relations with the cerebral and spinal.

There are no diseases so distinctly limited to one system as hemiplegia and tetanus, in their simplest forms. Hemiplegia frequently dissects the nervous system, as it were, and severs the cerebral from all the other functions. The voluntary movements of the side may be absolutely annihilated; the true spinal and ganglionic functions being unaffected. I have examined such cases with a peculiar interest; the cerebral system has been distinctly affected, whilst the true spinal has been as distinctly spared. 
It is almost needless to state that the reverse of this event occurs in tetanus. In this formidable disease the true spinal system is affected, the cerebral being, very long at least, uninvolved.

These views I shall illustrate, as before, by briefly adducing cases in point. I may here observe, that we have only to read the admirable volumes of $M$. Lallemand, of M. Andral, of Dr. Abercrombie, \&c. \&c., to be convinced that these distinctions have not been hitherto made, and that a fresh series of cases, in which they should be accurately marked, is wanting to this department of medical science. Let any one now mark, first the simplicity, and then the complexity of the symptoms of a case of hydrocephalus, or of apoplexy, and he will observe how the cerebral, the true spinal, and the ganglionic symptoms are successively involved in the disease, and how the symptoms, carefully noted, denote the progress of these terrible affections. Let epilepsy or tetanus be subjected to our observation, and we shall remark, that from the true-spinal system, the first seat of the disease, the other sub-divisions of the nervous system become implicated.

I now proceed to notice some of the diseases of the nervous system individually, in this point of view : the first of these is hemiplegia.

I. HEMIPLEGIA.

In cases of hemiplegia, the danger is precisely in proportion as spinal symptoms are superadded to those of the cerebral system. If the respiration be 
stertorous, if the deglutition be difficult, if the functions of the bladder, rectum, and sphincters be impaired, there is great danger; if these events continue for a considerable time, or if they supervene, the event is always fatal.

Case I.-A short time ago I visited a patient with Mr. Doubleday, of Blackfriars-road : there was anasarca, and the urine was coagulable. Dr. Bright was consulted. Suddenly an attack of the most complete hemiplegia supervened; the patient was conscious; the respiration and deglutition, and the power of the rectum, the bladder, and their sphincters, were unimpaired. The disease was limited to the cerebral function of voluntary motion in the arm and leg; but this was entirely destroyed; the foot was moved, however, on touching the sole of the foot! The patient survived the immediate attack, and was moved into the country.

Case II.-I visited a patient with Mr. Beane, of Peckham. He had been attacked with hemiplegia of the right side of the face, arm, and leg; there was slight stertor, and slight dysphagia, with choking. The true-spinal symptoms ceased on taking blood copiously; but the hemiplegia continued. When the upper and lower extremities were still motionless from any effort of volition, movements were induced by tickling, plucking a hair, or applying spoons, just taken out of hot and cold water, alternately. The hemiplegia was complete, but the spinal functions were in full force. The patient gradually but imperfectly recovered. 
Case III.-I visited another case with $\mathrm{Mr}$. Beane, in which the symptoms were the same, but more violent; there was some degree of coma; the respiration was stertorous, the deglutition difficult, and the functions of the rectum and bladder impaired. These symptoms continued in spite of active and appropriate treatment, and the patient died. A large coagulum existed in the right hemisphere, not, however, extending to the ventricles.

Case IV.-I visited the late member for Carlow with Mr. Dodd, of Portman-street. The patient was perfectly hemiplegic, but perfectly conscious; the speech was inarticulate, the tongue put out towards the right (the paralytic) side, the right arm and leg were absolutely motionless; the patient expressed by signs that he was powerless on the right side of the mesial plane; the respiration was not yet stertorous, but the deglutition was imperfect, and attended with choking; stupor and stertor gradually supervened, the deglutition became more and more imperfect, the bladder and rectum, and the sphincters, lost their powers. The respiration became attended with mucous rattle, irregular, and less frequent, and the pulse, from being slow, became accelerated,-affections of the ganglionic system. The powers of life gradually sank. No postmortem could be obtained.

These cases are sufficient to illustrate my proposition, that when, in hemiplegia, spinal symptoms exist, and do not very speedily yield to active reme- 
dies, or supervene in cases in which they did not exist originally, the event is inevitably fatal.

The spinal symptoms which exist at first, and gradually yield, probably depend on counter-pressure from congestion; this counter-pressure is relieved by blood-letting, \&c., and its effects cease. When, on the contrary, the spinal symptoms continue, in spite of the remedies, they probably depend on the extent of the effusion (as in Case III. and probably in Case IV.) ; and this cannot be remedied.

These views are confirmed by contrasting the cases of hemiplegia, almost invariably the effect of effusion of blood, with those of simple apoplexy.

II. OF APOPLEXY.

The purest, the simplest form of congestive apoplexy, is that which follows a violent fit of epilepsy. I was summoned to such a case in Pimlico, a short time ago, and will briefly detail its principal features:

Case V.-There were perfect stupor and stertor: I passed my finger over the eye-lashes and the conjunctiva, and the eye-lids were motionless; I dashed cold water on the face, and the respiration was unaffected by it. We took a large quantity, I think thirty or forty ounces, of blood from the arm: there was no change in the stupor, in the countenance, or in the pulse ; but now the eye-lids closed on touching the eye-lashes, and the patient sobbed deeply on dashing cold water on the face; afterwards, too, he became gradually more and more conscious. 
In this case, the state of congestion, and it was pure congestion, with its counter-pressure on the medulla oblongata, was relieved by the free detraction of blood; and the impressibility of the truespinal system, through the medium of its incident nerves, was restored.

I need scarcely remark, that in congestion of the cerebrum, in apoplexy, as well as in hemiplegia, if the symptoms of affection of the true-spinal system continue, the issue is fatal. In such cases the patient dies of asphyxia; and I cannot but think that tracheotomy might sometimes allow time for the operation of remedies or of nature's resources, and prevent a fatal result. It is well known to the members of this Society,* that this operation, performed by Mr. Sampson, of Salisbury, saved the life of a poor patient, dying from the apoplexy of deep intoxication.

I may here observe, that if the stupor and stertor continue, the next series of phenomena are those observed to result from defect of the function of the ganglionic system. The bronchi become clogged with mucus, and the intestines distended and tympanitic from flatus. M. Andral observes- " Le stertor de la respiration est en général un signe d'un très fâcheux augure, et il est rare que les individus qui le présentent d'une manière prononcée échappent à une mort prochaine. Pour l'expliquer, ou trouve sur le cadavre un en- 
gouement considérable du poumon, et beaucoup de mucosités spumeuses dans les bronches. C'est véritablement par la gêne de la respiration que succom. bent les sujets frappés d'hémorrhagie cérébrale, dans le cas où l'attaque est forte, et où ils meurent promptement."* It is obvious that the stertor is not explained in this manner; but that the bronchial and tracheal rattles which occur under these circumstances are so explained. They constitute, in effect, two orders of phenomena. The stertor depends on affection of the medulla oblongata; the crepitus or rattle on that of the ganglionic system. The latter is precisely the effect observed by Sir Benjamin Brodie, Sir Astley Cooper, and other physiologists, in animals in which the pneumogastric nerves had been divided. But the stertor depends upon the affection of the true-spinal system.

Not to detain the Society too long, I will here briefly advert to the interesting case of the hydrocephaloid disease of children. I need scarcely state, that similar phenomena are observed in hydrocephalus, and in the case of sinking from excessive loss of blood; I have also noticed them in extreme chlorosis in adults.

III. HYDROCEPHALOID DISEASE.

Case VI.-I attended the son of Mr. Howlett, in Thayer-street, in consultation with Mr. Grant. The little patient was four years old, and laboured under 
symptoms which seemed to denote the existence of hydrocephalus; there was a state of stupor: the eye-lids were only partially closed, and they were immoveable on the approach, and actual contact, of the finger; the respiration was irregular, and the pulse frequent. I observed that the phenomena presented by the eye-lids would afford a criterion, which would suggest both the diagnosis and prognosis. The history, and the cool and pale condition of the cheeks, suggested the hope that the symptoms depended more upon exhaustion than actual disease within the head. I ventured to give sal volatile, brandy, and nourishment. We had, in a short time, the pleasure of observing the eye-lids become impressible to the stimulus of the finger, the respiration to become regular, and the gradual recovery of the little patient was no longer doubtful.

IV. OF MANIA WITH AND WITHOUT PARALYSIS.

M. Leuret has recently drawn the attention of physicians to the distinction between mania with and without paralysis. The latter is, according to this estimable and intelligent writer, unattended by appreciable organic lesion; the former is the effect of disorganization of the brain.

Paralysis is, indubitably, the most characteristic sign of lesion of the cerebrum; and that, generally, in the form of a solution of continuity of the hemisphere opposite to the side affected. But I cannot agree with $M$. Leuret, that mania, unattended with 
paralysis, is unattended with organic lesion altogether. Only it is attended by a lesion of a different kind. As the former is generally one of interrupted continuity, this is generally one of an intra-vascular kind: thus coma and delirium are alike effects of deranged conditions of the cerebral circulation; both occur from excitement, and in a state of exhaustion; and $I$ have seen one form of mania cured in the most distinct manner by mercury, and another by steel.

This is a new and most important subject for inquiry. Puerperal mania; mania from exhaustion and anemia in general ; mania from mental shock and harass; all arise from a morbid, intra-vascular condition.

As disease, strictly limited to the cerebral system, is attended by cerebral symptoms only, so disease, limited to the true-spinal system, is marked by affection of the spinal functions only. In no case is this seen so distinctly as in tetanus.

\section{TETANUS.}

This disease is, in every respect, the most unequivocal example of an affection of the true-spinal marrow, through an incident and the motor nerves. All the functions of this sub-division of the nervous system are affected in the most violent form, whilst the cerebral functions are unaffected: the dyspnœea, the dysphagia, the constipation, the trismus, the emprosthotonos, the opisthotonos, the extreme susceptibility to causes of physical impression 
and agitation, and of mental emotion,-all mark an affection of the true-spinal system ; whilst the freedom from all affections of the senses and of the intellect, the absence at once of delirium and of coma, denote the normal condition of the cerebral system.

Baron Larrey observes, - " Les fonctions du cerveau restent toujours intactes jusqu'au dernier moment de la vie, en sorte que l'infortuné atteint de cette maladie se voit mourir. Je n'oserai hasarder aucune explication sur le défaut de communication au cerveau du principe morbide des nerfs affectés."

" Le malade ne peut plus avaler, ou n'avale qu' avec la plus grande peine. La poitrine est rétrécie, les contractions du diaphragme sont bornées; la respiration est courte et laborieuse. Les excrétions diminuent et se suppriment, surtout les selles."

M. Larrey adds, "Le malade tombe dans un état d'insomnie; lorsqu'il s'assoupit, il fait des rêves sinistres ; il s'agite, il s'inquiete, se tourmente, et cherche à sortir de l'état de gêne où le tiennent la rigidité de ses membres et le défaut de jeu des organes." *

Dupuytren states, "A mesure que la maladie marche, ou la voit s'accroître de plus en plus, et se montrer à tel point que le moindre bruit, la moindre secousse, les plus faibles émotions suffisent pour la mettre en jeu et faire entrer le système nerveux, et

* Mémoires de Chirurgie Militaire, tome i. pp. 238, 239. 
le système musculaire qui est sous sa dépendance dans un état de convulsion."

This is the very picture of an excited condition of the true-spinal system; the cerebral system is, notwithstanding, long spared, and it is only at a comparatively late period of the disease that delirium or stupor supervenes.

Similar remarks apply to the terrific case of hydrophobia.

VI. OF EPILEPSY.

Epilepsy seems to occupy a place on the limits of the cerebral and true-spinal systems: the first symptoms are sometimes apparently cerebral ; I am of opinion, however, that this appearance is frequently deceitful, and that the very first symptom is generally, if not always, one of the true-spinal kind. This first symptom is constriction about the throat, and closure of the larynx, more or less complete; then follow violent expiratory efforts and convulsive movements of the trunk and limbs. Intermediately, and even without the convulsive movements, the cerebrum is affected with congestion, and a multitude of cerebral symptoms occur : flashes of light, tinnitus aurium, the aura epileptica; a momentary oblivion; a state of terror, of delirium, or of unconsciousness, \&c. ; as parts of the general convulsion, the tongue is protruded and bitten, the fæces, the urine, or the semen expelled; as consequences of that convulsion, the cerebrum is congested, and there is coma. If this state continues, another 
order of symptoms takes place; the respiration becomes stertorous, and, at length, affected with mucous rattle, the true-spinal and ganglionic systems becoming fatally involved in the disease.

It is the constriction about the throat which assimilates epilepsy to the state of things which exists in strangulation, and which distinguishes it from hysteria. It is this circumstance which associates epilepsy with the crowing inspiration and the convulsions of children : all are laryngismal. In epilepsy, there is sometimes a crowing inspiration; the crowing inspiration and convulsion of infants are sometimes followed by epilepsy in subsequent years.

\section{OF SINKING.}

It is doubtful whether any set of diseases originates in the ganglionic system. This system, however, is frequently involved in other diseases, in a characteristic manner and degree, and the balance of nutrition and of absorption, and the condition of the secretions, with the actions of the heart, stomach, and intestines, become morbidly affected.

The gradual sinking from loss of blood, especially, seems to involve every part of the nervous system. There is mild delirium or stupor from affection of the cerebral system; there is a peculiar catching motion of the larynx and other organs of respiration, from affection of the true-spinal system, instead of the equable rhythmic movements observed in health ; there is an extreme frequency of the pulse; and there is a peculiar crepitant rattle, at first in the 
small, and eventually in the larger bronchi, and an. equally peculiar tympanitic distension of the intestines, from affection of the ganglionic system,-all of fatal import; at least, I have never known any one of these symptoms to supervene (uninduced by disease of the organ) without its leading to a fatal termination. The functions of the cerebrum, of the true-spinal system, and of the ganglionic system, seem to fail together.

\section{OF SHOCK.}

But if there be no diseases originating in the ganglionic system, there is a series of accidents which have their chief seat in this system. It is those which are caused by shock.

Shock may be mental or physical.

When a patient submits to an " operation de complaisance," the mental effort, the anxiety, the suffering, frequently lead to a state of dangerous and even fatal excitement. The crush of a limb frequently induces such depression, that the patient sinks without any apparent effort made to rally. In both these cases, the effect produced is much displayed in the ganglionic system ; the circulation, the secretions, are greatly affected.

I will merely adduce one experiment on this sub. ject for fear of being too prolix.

In the presence of a young Parisian student, I divided the spinal marrow in a frog. I pinched the toes, but there was no movement, no reflex action. My companion observed, "Ah, c'est fini ;" I replied, 
"Non, ce n'est pas commencé." In a few minutes, the reflex actions became obvious, and in a few minutes more, most energetic. We had examined the circulation previous to the division of the spinal marrow. It was most active. But immediately after that division, scarcely a movement was to be seen. Like the reflex actions, however, the vigour of the circulation was gradually restored.

In one frog, after the return of the circulation, I crushed the leg and thigh with a hammer. There was no sensation of course, the influence of the cerebrum having been removed. The circulation again immediately ceased. It again returned after a time.

These examples will be sufficient to illustrate the fact, that, in order to investigate the diseases of the nervous system with advantage, we must henceforth constantly inquire whether, and in what order, each of the sub-divisions of this system is affected. We must advert to the cerebral, the true-spinal, and the ganglionic functions, and trace the morbid influence upon each and all of them; we must inquire into the condition of the muscular irritability, the reflex and retrograde actions of the true-spinal marrow, and to the distinct actions and affections of volition, of emotion, and of the vis nervosa.

The cerebral, true-spinal, and ganglionic subdivisions of the nervous system, are, notwithstanding our artificial attempts to separate them, one in nature, and influence each other mutually. Sensation and volition combine to complicate and ${ }^{*}$ modify the functions of the true-spinal system; 
emotion modifies the functions both of the truespinal and ganglionic systems. Respiration is made rhythmic by the influence of volition; it becomes catching and irregular when this influence is withdrawn. Certain secretions become augmented under the influence of appetite, passion, emotion, and are comparatively scanty when these are dormant and unexcited.

The purest case of successive affection of cerebral, true-spinal, and ganglionic systems in disease, is, I think, afforded by the case of fatal sinking in exhaustion from loss of blood.

The cerebral system is first affected, and the previous symptoms of reaction give way to impaired vision and hearing, dozing or slight coma, and slight delirium when roused; - then the true-spinal system suffers, and the respiration loses its regular, even, and rhythmic character, and becomes slightly audible or stertorous, and each inspiration becomes accompanied by a sudden descent of the larynx, a symptom from which $I$ have never known a patient recover; deglutition is slightly impaired, and the larynx is irritated to choking and violent coughing by the admission of fluids, whilst the sphincters of the bladder and rectum fail ; lastly, the power of the ganglionic system fails too, and the respiration becomes marked by a slight crepitous rattle, like the catching of the larynx, a fatal symptom, and the intestines become tympanitic.

I have seen precisely the same order of symptoms, the same order of affections,-first of the cerebral, 
then of the true-spinal, and lastly of the ganglionic functions,- from shock to the nervous system. A sensitive person lost a favourite brother, suddenly; he fell into fever, with no definite symptoms; he at length became slightly delirious, then slightly comatose; then melæna, and then tympanitis manifested themselves; then the crepitous rattle in the respiration; and then followed all the phenomena of irregular respiration, and failure of the sphincters, which I have just described. A similar fatal series of symptoms was excited in a pale and chlorotic patient, by a similar mental affection. This is an interesting subject, not, I think, understood, and therefore requiring careful investigation.

The symptoms in fatal cases of coma from apoplexy, or epilepsy, occur in the same order : first, the respiration becomes affected; no effect is induced by dashing cold water on the face; the regular rhythmic movements of the respiration give place to audible, irregular, or catching inspirations; then bronchial, and lastly tracheal, rattles occur, with tympanitic distension of the intestines, and a similar state of the bladder. In a word, the cerebral, the true-spinal, and the ganglionic systems are affected in succession.

It would be interesting to examine the secretions in all these cases systematically. This, with so many others, presents promising subjects of future inquiry. 
II.-The influence of irritation, of pressure, of counter-irritation, and of counter-pressure, in disease within the cranium and spinal canal.

I. OF IRRITATION AND OF PRESSURE.

Important principles in the investigation of the diseases of the nervous system are irritation and pressure. Inflammation of the arachnoid of the cerebrum, and of the spinal marrow, presents us with an example of the former, and we have delirium in one case, and spasmodic action in the other; of the latter, the effusion of blood, or serum, affords us an example, and according as this takes place in the encephalon, or in the theca vertebralis, we have coma, or paralysis.

Not less important, and hitherto overlooked or neglected, are counter-irritation and counter-pressure, of which I shall therefore proceed to treat more particularly. The former is induced by slighter causes, as slight effusion into the ventricles; the latter, by the same causes carried to a greater degree.

II. COUNTER-IRRITATION.

There is one idea prevailing throughout M. Andral's admirable volume: it is, that the functional and organic lesions do not constantly accompany each other ; that, therefore, the diagnosis must be obscure. M. Andral observes, ${ }^{*-}$ " Toujours la

* Clinique Medicale, edit. 2. tome v. p. 58. 
même question se réprésente: pourquoi cette diversité de symptômes avec des lésions en apparence identiques?" And, in speaking of a case of hæmorrhagy between the arachnoid and dura mater, he observes,- "Ne sont ce pas là tous les signes du ramollissement du cerveaux."* But M. Andral's sphere of investigation has been too limited; he has not borne in mind the distinction of the different sub-divisions of the nervous system, with the distinct and significant symptoms attached to each of them.

The subject of counter-irritation, and that of counter-pressure, in diseases of the encephalon, have been overlooked; topics to which I now beg to call the attention of this Society: we have only to revolve in our minds the complex anatomy of the base of the encephalon and of the cranium, to be noticed more particularly immediately, and of the spinal canal and its contents, to see the importance of these two subjects. To these must be added the topics discussed in my three former Memoirs, and it will then be confessed that a new and unexplored field of observation is opened to us, and that new and positive means of diagnosis are in our hands.

There is another circumstance of great importance. M. Andral speaks of irritation of the cerebrum as the cause of abnormal muscular contractions. Now, in our investigations into the nature of cerebral diseases, we must remember one circumstance ; it is impossible to induce muscular action by any irritation of

* Op. cit. 9. 16. Compare also page 4. 
the substance of the cerebrum itself. Whenever, therefore, there are spasmodic affections in diseases of the nervous system, we must conclude that the spinal system is involved, either primarily or secondarily, in the disease. Irritation of the cerebrum may induce delirium and other disorders of the cerebral functions ; congestion of the cerebrum may induce coma, paralysis, \&c. But if these morbid conditions of the brain be attended by spasmodic or other deranged actions, it is because the true-spinal system is involved in the disease, or affected by it in the way of irritation, counter-irritation, or of pressure, or counter-pressure. Hence we observe the symptoms of spasm in various diseases of the encephalon, the condition being, not the nature of the disease, but that they produce these intermediate effects. Time, as is well known, is a very important element in this problem; and why is it so? The fact is to be explained on the same principles. The very same lesion occurring quickly, will produce effects which will be totally absent if it creep on slowly. In the former case, we have the effects of irritation and pressure, or of counter-irritation and counter-pressure ; in the latter, the cerebrum has so accommodated itself to the new state of things, probably by the altered condition of its vessels, as to avoid these effects, except towards the close of the disease.

We need not, therefore, now view with surprise the fact that the same lesion, as found post-mortem, had been attended by a totally different series of 
symptoms during life, any more than the other fact, that, in the different periods of that lesion, the symptoms have been different.

The symptoms frequently subside too and reappear. If the disease be not regularly progressive, the encephalon accommodates itself, as I have stated, and the symptoms disappear; if now the disease proceeds, the symptoms also return. At least all this may be.

A rapid effusion of serum may resemble hæmorrhage or ramollissement in its effects; a slow effusion may merely obscure the intellectual faculties.

One of the earliest symptoms of hydrocephalus is vomiting. Is this the effect of counter-irritation? Afterwards this symptom ceases, and there is torpor of the digestive tube. Is this the effect of counterpressure? In the absence of positive proof, I present this as a probable conjecture, and as a subject for subsequent inquiry. In a case of tubercle, seated in the median lobe of the cerebellum, observed by Dr. P. Hennis Green, the same symptom of vomiting, arising probably from irritation of the medulla oblongata, was observed. Similar remarks apply to the state of the pupil.

It is not, therefore, the disease, but its effects upon the brain and spinal marrow, which is the source of the symptoms. If ramollissement, effusion, a tumour, \&c., produce similar effects on these textures, the same affection of the functions, the same symptoms, will be observed. 
III. OF COUNTER-PRESSURE.

Having pointed out the distinct affection of a cerebral function, in pure hemiplegia, and the implication of the true-spinal functions when, with or without hemiplegia, there is congestion of the cerebrum, and consequent counter-pressure on the medulla oblongata, I must here briefly notice the effect, first, of undue, and secondly, of defective counter-pressure, a little more particularly.

It is well known, from the experiments of $M$. Flourens especially, that irritation of the cerebrum has no influence in inducing spasmodic action. Whenever, therefore, spasmodic symptoms occur in diseases of the cerebrum, it must, as I have already stated, be on a principle different from that of irritation of the substance of the cerebrum itself; it must be from an impression made upon parts of the nervous system in which the property of exciting spasmodic action on being subjected to irritation resides ; these parts are the tubercula quadrigemina, the medulla oblongata, the intra-cranial nerves, \&c.

That undue counter-pressure on the medulla oblongata may, and actually does, excite convulsion, is proved by the following facts : In the interesting case, most anxiously watched and accurately detailed to me by my friend Mr. Toogood, of Bridgewater, of his own little girl, aged thirteen months, the croup-like convulsion occurred repeatedly, until one day, when the bones of the cranium separated, and 
the convulsion ceased. In a case of spina-bifida, related to me by Mr. Herbert Evans, of Hampstead, there was a croup-like convulsion whenever the little patient turned so as to press upon the tumour. In the case of an anencephalous foetus, described by Mr. Lawrence, convulsion was produced on pressing on the medulla oblongata. In a case of meningitis, given by Dr. Abercrombie, the anterior fontanelle became very prominent. Pressure upon it induced convulsion. Hypertrophy of the brain affords an argument of the same kind : it induces convulsion, except in the case in which the cranium grows with the encephalon. These and other facts lead me to think that convulsion arising from cerebral disease is thus to be explained. I shall merely adduce the case of Dr. Abercrombie.

Case VII._- A child, aged eight months old, died on the 13th March 1818, of an illness which had continued more than three weeks. It began with fever, restlessness, and quick breathing ; afterwards, there were frequent convulsive affections, with much oppression, and at last severe convulsions, squinting, and coma. At an early period of the complaint, there was observed a remarkable prominence of the anterior fontanelle; in the second week, this increased considerably ; and, in the third week, it was elevated into a distinct circumscribed tumour, which was soft and fluctuating, and pressure upon it occasioned convulsion. It was opened by a small puncture, and discharged at first some purulent matter, afterwards bloody serum. No 
change took place in the symptoms, and the child died four days after."*

That defective pressure will produce the same effects, is proved by the following most interesting case.

Case VIII.- "M. Bérard, jeune a lu à l'Académie de Médicine, dans sa séance du 22 Octobre, 1833, l'observation d'une tumeur fongueuse de la dure mère. Une circonstance bien remarquable de cette observation, c'est qu'immédiatement après que la tumeur eût été enlevée par M. Bérard, avec la dure mère avec laquelle elle adhérait, le malade fut pris de perte de connaissance et de mouvemens convulsifs du trouc et des membres. M. Bérard, pensant que la brusque soustraction d'une partie de l'envelope resistante du cerveau causait cẹs accidens, appliqua de suite sur toute la partie dénudée de l'organe un morceau d'agaric, sur lequel il pressa modérément avec la paume de la main. Sous l'influence de cette compression, les convulsions cesserent et l'intelligence se rétablit." $\dagger$

The rigidity of the muscles in cases of ramollissement, and some other cerebral diseases, doubtless depends upon the same principle. Every observer will now distinguish, from this phenomenon of an acute disease, the chronic rigidity which supervenes in cases of hemiplegia. $\neq$

* On the Brain and Spinal Cord. Ed. 3. p. 57.

$\uparrow$ Andral, op. cit. t. v. p. 556.

$\ddagger$ An erroneous view, $I$ believe, is taken of this subject by $M$. Andral, vide op. cit. pp. $363-365$. 
It may be stated in conclusion, that the truespinal symptoms which occur in cerebral attacks arise from counter-pressure : when the source of this is permanent, as in hæmorrhagy, the effect is permanent too, and the case fatal; when it is remediable by blood-letting, as in congestion, the cause and its effects are removed together.

The convulsions induced by hæmorrhage depend upon a similar subtraction of the intra-vascular pressure of the blood in the medulla oblongata. I need scarcely observe, that, in order that these effects of undue or deficient pressure may be induced, it is necessary that such changes in this pressure be effected rapidly. No such effects of pressure, slowly altered in chronic disease, are observed.

This subject is admirably illustrated by Sir Astley Cooper's experiments on the effects of withdrawing the force of the arterial blood, by applying ligatures or pressure on the vertebral arteries, which I shall notice immediately.

I now beg very briefly to draw the attention of the Society to another interesting topic, viz. :-

III.-The special anatomy of the base of the encepha-

lon in reference to diseases of the nervous system.

It is unnecessary for me to do more than advert to the important anatomy at the base of the cranium,-the course of the various nerves, \&c., and most particularly the position of the medulla oblongata, so apt to be affected by irritation and 
pressure, counter-irritation, and counter-pressure, and the consequent source of so many symptoms, and especially of the affections of the pupil, of the respiration, of deglutition, of the sphincters, \&c. Another subject of interest is the peculiar position of the tentorium, leaving in its centre a sort of internal foramen magnum. By this membrane, the direct effects of pressure from ramollissement and other diseases of the cerebrum on the parts below are prevented, whilst an oblique or counter-pressure is the result, with its special effect on the symptoms. This result is modified too by the semi-solid, semifluid texture of the various parts of the encephalon.

It is these circumstances, combined with another element of the proposition-that of time,-which frequently leads to an effect which I shall notice immediately ; viz., the difference of symptoms with identity of lesion, and the similarity in the symptoms when the lesion is dissimilar. The same morbid change will produce very different effects, developed as an acute and as a chronic disease; and different physical lesions will produce nearly the same results if developed in nearly equal times.

In a chronic affection, the cerebral substance yields, its vessels becoming empty, and pressure is not induced. In acute affections, on the contrary, pressure is made upon contiguous, and counterpressure upon distant parts, with their appropriate symptoms. By degrees, even in the latter case, the cerebral substance yiekds, and the symptoms, in the less severe cases, subside, and even disappear. 
But this last subject belongs to the next question :-

IV.-Why, with similar symptoms, have we dissimilar morbid appearances, and vice versa? and, what are the diseases of the nervous system, in which we find no morbid appearances on a post-mortem examination?

If the source of the symptoms be not the mere lesion of a function, induced by the lesion of a special part or organ of the encephalon, but the effect of irritation and counter-irritation, of pressure and counter-pressure, it is obvious that these primary effects, and their effects in their turn, may result from any disease, if the times be similar, whatever that may be.

It is accordingly to the history that we chiefly have recourse for the diagnosis of cerebral diseases, and especially to that of the seizure and first stage; at their close, almost all diseases of the encephalon are alike : almost all terminate by coma, paralysis, convulsions, stertor, and impaired actions of inges-. tion and egestion, and of the orifices and sphincters, from compression of cerebrum and medulla oblongata.

There is another view of this important subject. Morbid changes take place towards the close of many diseases, which do not properly or at all constitute the disease. In exhaustion, in chlorosis, in delirium tremens, effusion of serum, and even of lymph, occurs. In disease of the encephalon itself, 
such effusion also takes place, late in its course, and complicates the original disease. Further:-

It is plain that in the immediate effect of shock applied to the nervous system, whether this be mental or physical, we can expect no morbid physical lesion.

It is equally plain, that, as the immediate effect of exhaustion of the vascular system on the nervous system, we should likewise discover no organic change.

It is equally plain, that, in the immediate effects of strychnine and of the hydrocyanic acid, we should also observe the absence of all perceptible physical change.

Now these effects are the types, as it were, of a series of diseases in the human subject.

Shock and exhaustion induce delirium, and even mania; a wounded or poisoned nerve becomes the cause of tetanus and hydrophobia; the hydrocyanic acid induces the almost sudden cessation of the functions. We could not, in any of these cases, expect organic changes.

But though there may be no such change as we have been in the habit of looking for in our postmortem examinations, it does not follow that there may be no physical change whatever. The effect of shock may be altogether inscrutable; but the effects of exhaustion may, even in the commencement, be perfectly real, but intra-vascular. This is the case in some forms of mania,-in puerperal mania, the mania from undue lactation, \&c. 
I must here adduce two interesting facts, one observed by myself, the other an experiment of Sir A. Cooper.

The animal which dies from loss of blood, dies convulsed. The cause of this convulsion is the anæmious condition, not of the brain, but of the spinal marrow; this is ascertained in the sheep in the following manner :-

Experiment.-The butchers usually divide the large vessels of the sheep, and the animal dies in the midst of convulsions. I begged that the spinal marrow might be first divided most completely, and then the blood be allowed to flow from the divided blood-vessels : again there were violent convulsions, -an event which could depend on the anæmious state of the spinal marrow alone, the influence of the brain having been removed.

"I tied," says Sir A. Cooper, "the carotid arteries (in a rabbit). Respiration was somewhat quickened, and the heart's action increased; but no other effect was produced. In five minutes, the vertebral arteries were compressed by the thumbs, the trachea being completely excluded. Respiration almost directly stopped-convulsive struggles succeeded-the animal lost its consciousness, and appeared dead. The pressure was removed, and it recovered with a convulsive inspiration. It lay on its side, making violent convulsive efforts, breathed laboriously, and its heart beat rapidly. In two hours it had recovered; but its respiration was

voL. XXIV. 
laborious."* The compression was repeated five times with the same effects. The want of the due supply of blood to the medulla oblongata induced convulsive actions.

It is to the hidden effect of shock, and the intravascular change in exhaustion, and their consequences, that I now wish to direct the attention of the members of this Society. My design being merely to point out objects for observation, I do not propose to enter upon the discussion of any of them on the present occasion.

I shall conclude by observing, that besides shock and exhaustion, there are other causes of disease, or rather of derangement, of the nervous system, the effects of which require new investigation. Such are the effects of alcohol, seen in delirium tremens, the effects of sexual excesses, seen in some cases of paraplegic affection. The affections of the head in arthritis and in dyspepsia are of the same kind. Of the same character, and of extreme importance, are the effects of exposure of portions of the nervous system, especially of the spinal marrow and superficial nerves, to extreme cold. But I must conclude these remarks, and will do so by adducing interesting paragraphs from Dupuytren, M. Gendrin, and M. Andral.

" Du reste," says the first, "les symptômes et l'autopsie se réunissent pour démontrer que la

* Guy's Hospital Repoorts, vol. i. p. 465. 
tétanus est une affection essentielle nerveuse, et sans lésion organique qui lui soit propre."

" J'ai observé," says M. Gendrin, " plusieurs hydrophobes, et j'ai assisté à l'ouverture des cadavres d'un plus grand nombre encore ;" " je n'ai jamais vu la moindre trace d'inflammation ou de lésion quelconque dans les organes encéphalo-rachidiens, ni dans les nerfs ganglionares."

M. Andral observes, "Que le nombre d'altérations connues est petit à côté de celui des lésions qu'on ignore! Les cas où, après la mort, ou trouve quelque chose d'appréciable pour le scalpel sont les plus communs pour les autres organes; pour le système nerveux c'est tout l'opposé : les cas où on rencontre des lésions sont de beaucoup les plus rares. Cette assertion paraîtra paradoxale à ceux qui ne connaissent des lésions nerveuses que les trois ou quatre maladies qu'on observe dans les hôpitaux; mais les affections nerveuses se competent par centaines, et pour ne parler que de ces grandes perturbations qui portent sur le mouvement, sur la sensibilité, sur l'intelligence, où est la lésion dans ces cas? La plupart du temps on n'en trouve aucune, ou celles qu'on observe n'ont aucun rapport avec les désordres fonctionels."

There is still one other topic which I must briefly notice in connection with the present subject. It is

THE EFFECTS OF EXPOSURE TO SEVERE COLD.

I particularly noticed the effects of exposure to severe cold, during my experiments on hibernation, 
published in the Philosophical Transactions of 1823. Whilst exposure to a moderate degree of cold conduces to the state of hibernation, a physiological and preservative condition, exposure to intense cold induces torpor, a state totally different, but not sufficiently distinguished from the former, of a pathological character, and of fatal tendency. In the state of hibernation, the animal is dormant and motionless, but the actions excited are perfectly regular; in the state of torpor, on the contrary, the animal moves about, but the movements are, in the highest degree, irregular and tottering. I always observed that the state of torpor issued in death.

In man, similar effects are produced: the lips cannot articulate, the fingers cannot grasp any minute object, the feet and legs cannot sustain the individual, who has been thus benumbed by exposure to cold.

Exposure to extreme heat or cold equally induces spasmodic action in the muscular system. A young gentleman having been ordered a warm bath, mistook the temperature, and exposed himself to such a degree of heat as induced general spasmodic action of the most painful kind. The effect of too intense a cold on swimmers is a fact too well known to be further noticed.

When the exposure to cold is more partial, effects on both the sentient and motor portions of the nervous system are produced, which have this characteristic :- there is at first paralysis, and afterwards 
undue action. The first effect of exposure to cold is numbness in the fingers; this usually yields to pain, vulgarly termed " hot-ache," especially if the warmth be restored too rapidly. In a relative of mine, exposure to a severe wind, with sleet, induced perfect numbness of one side the face; this paralysis subsided, and gave way to severe tic douloureux. A lady, whose case I shall detail more at length immediately, was exposed to severe cold with wind. The next day she arose from bed with paralysis of one side of the face! This paralysis yielded by degrees to spasmodic tic.

Exposure to cold is a far more frequent cause of paralysis than is generally supposed. Such an effect on the face has been designated, in common language, (which frequently involves an important truth,) $a$ blight. Cases of paralysis of the face, from exposure to cold, are detailed by Dr. Powell in the fourth volume of the Transactions of the Royal College of Physicians. There is a poor little boy, residing near me, of six years of age, whose limbs are nearly paralytic, in consequence of a long and most criminal exposure to cold by a nurse. Some years ago, I visited a gentleman perfectly paraplegic, from long exposure to intense cold on the outside of a coach. Baron Larrey speaks of permanent paralysis, left by exposure to intense cold during the campaign in Russia. Paralysis, happily of a less permanent character, has been experienced by every one under similar circumstances.

But the point to which I must now revert, and to 
which $I$ beg to call the attention of the members of this Society, is, that the first effect of a partial but severe exposure to cold is paralysis; whilst the more remote effect is undue action. This principle I proceed to illustrate by a most interesting case of spasmodic tic, interesting in many points of view. It is given in the form of a letter, written to an eminent authority on this subject.

" DEAR SIR,

"I saw Lady - —, now Lady —, before a recent visit to Switzerland, and I have this day, after my return, seen the correspondence between you and Mr. — case. There has certainly been some misapprehension of this case, for Mr. - speaks of the ' affection having shifted from one side of the face to the other ;' and you say, 'there is certainly a degree of weakness of the portio dura of the left side.' Now I believe there has never been a change of the side affected, and that it is not the portio dura of the left side which is weakened, but that of the right which is irritated, so producing spasm.

" This view I will explain :-

"The probable cause was exposure to a severe cold wind.

"When the affection first took place, the face was drawn towards the left side, but the eye-lid of the right was paralysed, the eye requiring the application of the finger to close it, and being more open than the left, the left being in its natural state. 
After a time, the face was drawn to the right, and now the right eye, which gaped before, became less open than the left; but the left was still in its $n a$ tural state.

"In a word, the change was from paralysis to spasm, but it was of the same side-always the right; and now, it is not weakness of the left portio dura, but irritation of the right. The right eye was always morbidly affected, first by paralysis, now by spasm; the left has always been natural.

"The sensibility has always been unaffected.

" At this time, every thing is spasmodic, and that of the right side of the face.

"The right eye-lid is usually more closed than the left ; and when closed by an act of volition, it is drawn a little awry (to the right); and during laughing, it is spasmodically closed without an act of volition.

"'The whole right side of the face is spasmodically drawn to the right on laughing, or speaking, or eating on the right side of the mouth, and a new dimple is formed on the right side of the chin. All is normal on the left side, which is only drawn a little by the spasmodic action on the right. The eye-lid is natural, and mastication is naturally performed on this side, except from the decayed state of the teeth. It is plain that, whatever the cause might be, and I suspect it was exposure to severe cold, it first induced that change in the portio dura of the right side which produced paralysis, and which, being diminished, is now characterized by 
spasm. It is the right and not the left side, therefore, to which our remedies must be applied, if applied near the motor nerve, immediately or remotely the seat of the disease. I have seen several cases beginning with paralysis and proceeding to spasmodic affection of the portio dura of the same side. I have also seen one unequivocal case of paralysis affecting successively the portio dura of both sides, after an interval of several years.

"I am, dear Sir, \&c.

“ 14, Manchester Square,

September 20th, 1840.

"To- -

From the misapprehension in regard to this affection, to which $I$ adverted in the above letter, the remedies were actually prescribed to be applied to the unaffected side of the face !

I need scarcely state, that in these cases we should scarcely expect to find any post-mortem appearances.

I conclude by stating, that, in all future cases of disease of the nervous system, we must observe the various points which have been brought before the Society, in the order given in the following Table :- 
TABLE.

I. The Cerebral Symptoms.

1. Excess, or defect, in the Senses; Pain.

2. Delirium; Coma.

3. Paralysis.

II. The true-Spinal Symptoms.

1. Spasm, clonic or tonic.

2. Paralysis, -in regard to

1. The functions of Ingestion.

2. The functions of Excretion.

3. The Muscular System generally.

3. Reflex and Retrograde Actions.

4. Irritability of the Muscular Fibre.

III. The Ganglionic-in regard to

1. Nutrition.

2. Temperature.

3. The Secretions, especially those of

1. The Bronchi.

2. The Stomach and Intestines.

3. The Kidneys and Bladder.

IV. The Effects of Emotion.

V. The Effects of Shock.

VI. The Effects of Counter-pressure, \&\&.

What is now wanted is a series of such cases, taken with the care and accuracy of M. Louis, and then as carefully analysed and compared. 


\section{POSTSCRIPT.}

In this postscript I wish to call the attention of the profession to a source of the symptoms in encephalic affections not hitherto noticed by any medical writer:-it is the influence of irritation of the membranes of the brain in inducing spasmodic affections.

In an important experiment which I propose to lay before the Society in the next session, I found that although every kind of irritation, puncture, laceration, \&c., of the cerebrum and cerebellum was entirely inoperative, yet that laceration or pinching of the dura mater immediately induced peculiar spasmodic movements of the eye-ball, the eye-lids, the head, \&c.

These effects are probably induced through branches of the trifacial nerve, which, as in the recurrent of Arnold, is well known to impart branches to the dura mater, and which may do so to the other membranes within the cranium.

The whole subject is in need of investigation. Our way must be pointed out, first, by experiment. This must be followed by observation. The membranes within the cranium and spinal canal, the other serous membranes, and the internal textures in general, must be submitted to a similar examination.

I also propose to submit the questions discussed in the present Memoir, to experimental inquiry. 